\title{
Guidelines
}

Skin

Appendage

Disorders

\section{Precision Medicine and the Practice of Trichiatry: Adapting the Concept}

\author{
Ralph M. Trüeb ${ }^{a}$ Vicky M.L. Jolliffe ${ }^{b} \quad$ Antonia Fellas Régnier ${ }^{a}$ \\ Hudson Dutra Rezende ${ }^{a}$ Sergio Vañó-Galván ${ }^{c}$ Daisy Kopera ${ }^{d}$ \\ Demetrios loannides ${ }^{e}$ Maria Fernanda Reis Gavazzoni Dias ${ }^{f}$ \\ Melanie Macpherson ${ }^{9}$ Aida Gadzhigoroeva ${ }^{\text {h }}$ Julya Ovcharenko ${ }^{i}$ \\ Won-Soo Lee' Sundaram Murugusundramk ${ }^{k}$ Sotaro Kurata' \\ Mimi Chang $^{\mathrm{m}}$ Chuchai Tanglertsampan ${ }^{\mathrm{n}}$
}

\begin{abstract}
${ }^{a}$ Center for Dermatology and Hair Diseases Professor Trüeb, University of Zurich, Zurich, Switzerland;
${ }^{b}$ The Royal London Hospital, London, UK; ${ }^{C}$ Ramon y Cajal Hospital, University of Alcala, Madrid, Spain; ${ }^{d}$ Center of

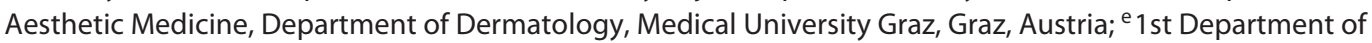
Dermatology-Venereology, Aristotle University Medical School, Hospital of Skin and Venereal Diseases, Thessaloniki, Greece; ${ }^{f}$ Department of Dermatology, Centro de Ciências Médicas, Hospital Universitário Antonia Pedro, Universidade Federal Fluminense, Niterói, Brazil; ${ }^{9}$ Department of Dermatology and Venereology, San Gabriel Clinic,

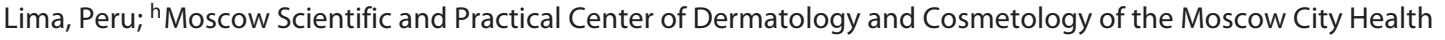
Department, Moscow, Russia; 'General and Clinical Immunology and Allergology Department, School of Medicine, V.N. Karazin Kharkiv National University, Kharkiv, Ukraine; 'Department of Dermatology, Yonsei University, Wonju College of Medicine, Wonju, South Korea; ${ }^{k}$ Chennai Skin Foundation \& Yesudian Research Institute, Chennai, India; 'Beppu Garden Hill Clinic \& Kurata Clinic, Beppu City, Japan; m Prince of Wales Hospital and the Chinese University of Hong Kong, Hong Kong, China; ${ }^{n}$ Department of Dermatology, Mae Fah Luang University Hospital (Bangkok), Bumrungrad International Hospital, Bangkok, Thailand
\end{abstract}

\section{Keywords}

Trichiatry · Comorbidity · Precision medicine · Panomics . Targeted therapies

\begin{abstract}
Evidence-based medicine (EBM) aims for the ideal that healthcare professionals make conscientious, explicit, and judicious use of the best available evidence gained from the scientific method to clinical decision-making. It seeks to assess the strength of the evidence for benefits of diagnostic tests and treatments, using techniques from science, engineering, and statistics, such as the systematic review of med-
\end{abstract}

ical literature, meta-analysis, risk-benefit analysis, and randomized controlled trials. The limited success rate of EBM therapies suggests that the complex nature of hair loss may be inadequately served by the present levels of evidence, and that physicians treating hair loss may have fallen short of adequately researching a robust evidence to underpin their practices. Against this backdrop, the concept of precision medicine (PM) is evolving. PM refers to the customization of medical care to the patient's individual characteristics based on the patient's genetic background and other molecular or cellular analysis, while classifying patients into subpopulations that differ in their susceptibility to a particular medical condition, in the biology or prognosis of those

\section{KARGER}

(C) 2019 S. Karger AG, Basel

E-Mail karger@karger.com

www.karger.com/sad
Prof. Ralph M. Trüeb, MD

Center for Dermatology and Hair Diseases Professor Trüeb

Bahnhofplatz 1A

$\mathrm{CH}-8304$ Wallisellen (Switzerland)

E-Mail r.trueeb@derma-haarcenter.ch 
medical conditions, or in their response to a specific treatment. With the advances in hair research, the powerful tools of molecular biology and genetics, and innovative technologies, we have the robust scientific data and tools to adapt the concept of PM to the practice of trichiatry. Finally, databases pertaining to the development and efficacy of PM must be analyzed and be used to form the basis of evidence-based personalized trichiatry.

(c) 2019 S. Karger AG, Basel

The history of medical reasoning has been one of an evolution from magical medicine (e.g., tribal medicine and shamanism) through speculative medicine based on speculative philosophical systems rather than the empirical and experimental approach, pragmatic medicine dealing with things in a way that is based on practical rather than theoretical considerations, to today's evidencebased medicine (EBM) and precision medicine (PM).

EBM seeks to assess the strength of the evidence of risks and benefits of diagnostic tests and treatments, using techniques from science, engineering and statistics, such as the systematic review of medical literature, meta-analysis, risk-benefit analysis, and randomized controlled trials [1]. EBM aims for the ideal that healthcare professionals should make conscientious, explicit, and judicious use of the best available evidence gained from the scientific method to clinical decision-making. However, the limited success rate of evidence-based therapies in managing hair loss suggests both that the complex nature of hair loss may be inadequately served by the present levels of evidence for therapies, and that physicians treating patients with hair loss may have fallen short of adequately researching a robust evidence to underpin their practices.

Against this backdrop, the concept of PM is evolving. In contrast to EB, PM refers to the customization of medical care to the individual characteristics of the patient. It does not literally mean the creation of treatments that are unique to a particular patient, but rather the ability to classify patients at hand into subpopulations that differ in their susceptibility to a particular medical condition, in the biology or prognosis of those medical conditions they may develop, or in their response to a specific treatment. For this purpose, diagnostic testing is employed for selecting appropriate and optimal therapies based on the context of a patient's genetic background or other molecular and cellular analysis. The tools employed in PM include molecular diagnostics, biochemical analytics, and imaging [2]. Preventive or therapeutic interventions can then be concentrated on those who will benefit, sparing expense and side effects for those who will not. The con- cept has evolved from cancer medicine, where it is also referred to as precision oncology and has paved the way to targeted cancer therapies with success.

There is considerable overlap between the terms PM and personalized medicine. Personalized medicine is an older term, however, the word personalized may be misinterpreted to imply that treatments are being developed uniquely for each individual; while in PM the focus is on identifying subgroups of patients for which approaches will be effective based on the diagnostic tools of PM.

We have recently proposed the term trichiatry to describe physicians trained in the evaluation and management of patients with hair loss, who have complex and challenging needs. The quality and stringency of the trichiatrist's graduate medical training is identical to that of fellow physicians of any other discipline, allowing the trichiatrist to be comprehensive in counselling patients, prescribing medication, conducting physical examinations, ordering laboratory tests, and participating with the other medical disciplines in the diagnosis and treatment of hair problems as they may relate to systemic disease [3]. With the advances in hair research and clinics, the powerful tools of molecular biology and genetics, and innovative technologies, we now have enough robust scientific data and tools to adapt the concept of PM to the practice of trichiatry for the management of androgenetic alopecia, alopecia areata, and the scarring alopecias.

Ideally, we should strive to develop PM alongside EMB to ensure optimum clinical practice and to gain evidence base for personalized medicine. Indeed, PM must undergo the same rigorous analysis as EBM so that it too can form part of an evidence-based practice.

\section{Androgenetic Alopecia}

Androgenetic alopecia is the single most frequent cause of male and female hair loss. It is understood to represent a hereditary and androgen-dependent, progressive thinning of the scalp hair that follows a defined pattern, though there exist significant differences with respect to frequency, age of onset, and pattern of alopecia between male and female androgenetic alopecia. In fact, there is a considerable age- and sex-dependent, as well as interindividual variability in the clinical presentation, the course, and the response to treatment, suggesting heterogeneity of pathogenetic factors in androgenetic alopecia that have to be taken into account for a personalized therapy.

Gene polymorphism diagnostics have been suggested both for risk assessment [4], and for prognostication of 
response to treatment with the 5alpha reductase inhibitors [5], as well risk of long-lasting adverse effects [6].

Since the hair growth-promoting effect of minoxidil is due to the actions of its sulfated metabolite, minoxidil sulfate, for clinical efficacy, minoxidil has to be sulfated by a group of enzymes known as sulfotransferases, some of which are expressed in the hair follicle with wide interindividual variations in the level of enzyme activity. Therefore, enzymatic assay of sulfotransferase activity in plucked hair follicles may predict response to topical minoxidil therapy [7-9].

Relevance of dermoscopic [10] or histological evidence of associated follicular inflammation and fibrosis found in 40\% of androgenetic alopecia has also been demonstrated [11]. Morphometric studies in male androgenetic alopecia treated with topical minoxidil showed that a significantly lesser proportion of those with associated microinflammation had regrowth in response to treatment, in comparison to those without inflammation and fibrosis [11].

Traditionally, the medical focus has been either on hair loss or on the condition of the scalp in terms of specific dermatological diseases. Indeed, the proximate structural arrangement of the scalp and hair leads to an interdependent relationship between the two. There is a wealth of observational data on specific dermatological conditions of the scalp providing the evidence for the role of the scalp condition in supporting the production of healthy hair [12]. The scalp is a rich environment for microbes. Ecologically, sebaceous areas have greater species richness than dry ones [13], with implications both for skin physiology and pathologic conditions. Specifically, the microbiome of the scalp and its relationship to the respective scalp pathologies, such as dandruff and seborrheic dermatitis [14], psoriasis [15], and atopic dermatitis are currently in the focus of investigation [16-20].

Finally, comorbidities, specifically elevated androgen levels in women with androgenetic alopecia, such as in the polycystic ovary syndrome, indicate the necessity for a respective adaptation of treatment to include antiandrogen therapy for efficacy [21], and assessment for associated abnormalities and risk factors (metabolic syndrome, cardiovascular disease, endometrial carcinoma).

Moreover, obvious differences in clinical response of female androgenetic alopecia to clinical trials with oral finasteride [22-29] have led to the suggestion that not all types of hair loss in women have the same pathophysiology (i.e., a distinction should be made between alopecia with early [premenopausal] or with late [postmenopausal] onset, and with or without hyperandrogenemia [30].
Hypothyroidism is one comorbidity with an adverse effect on androgenetic alopecia and a particularly high frequency in women [31-36], another one is iron deficiency. The existing controversy surrounding the relevance of iron stores in androgenetic alopecia, and other types of hair loss such as telogen effluvium and alopecia areata [37-48], indeed highlights our premise of the limitation of EBM in managing patients with hair loss, since there is a paucity of clinical trials evaluating therapeutic response to iron supplementation in managing these disorders.

\section{Alopecia Areata}

Alopecia areata is understood to be of autoimmune origin with an organ-specific, T cell-mediated assault on the hair follicle at the level of the bulb. A peribulbar lymphocytic infiltrate induces hair follicle keratinocytes to undergo apoptosis resulting in inhibition of cell division in the hair matrix. Some patients lose hair in only a small patch, while others may have more extensive or less frequently diffuse involvement. Alopecia totalis is the loss of all scalp hair, alopecia universalis is the loss of all scalp and body hair. The progress of alopecia areata in an individual patient is unpredictable, though risk factors have been proposed for prognostication. From a clinical point of view, a large surface area, a long disease duration, and associated nail abnormalities (trachyonychia) have been connected with a poorer prognosis [49].

Ikeda [50] originally proposed a classification of alopecia areata depending on associated comorbidities (atopic disease, familial arterial hypertension, and autoimmune endocrine disease) again reflecting on heterogeneity of the disease with implications for prognosis and the risk of total loss of hair.

Today, laboratory investigations for comorbidities screening is suggested in alopecia areata to detect other associated autoimmune conditions, specifically autoimmune thyroid disease [51-54], pernicious anemia [55], lupus erythematosus [56], and in children celiac disease [57-60], and/or comorbidities that may affect the disease course, such as deficiencies of iron [40], of zinc [61, 62], or of vitamin D [63-66], and HIV infection [67].

Contributing genetic factors have been implicated early in the observation of familial occurrence of alopecia areata. Alopecia areata fits the pattern of a complex genetic trait with specific genes contributing both to susceptibility and to disease severity [68]. More recently, genome-wide association studies have unraveled genetically controlled immunologic pathways $[69,70]$, deepening 
our understanding of the events leading to the disease and identifying possibilities for novel targeted treatments of alopecia areata, such as the inhibition of Janus kinases [71-76].

In view of the high variability of clinical response of long-standing, widespread disease to the current treatment modalities (i.e., topical immunotherapy with diphencyprone), there is a clear need for genetic or immunological markers for prediction of treatment outcome in the individual patient.

\section{Scarring Alopecias}

The scarring alopecias represent a diverse group of disorders that cause permanent destruction of the pilosebaceous unit and irreversible hair loss. Scarring alopecias pose both a diagnostic and therapeutic challenge to the practitioner. Accurate diagnosis is a prerequisite to therapy and based on a careful patient history, clinical examination, microbiological studies, and scalp biopsy, while there is no diagnostic biological marker for most entities. Challenges related to the treatment of the scarring alopecias include patient's delay, when irreversible scarring has already occurred; empiric and nonspecific therapies, since the causes are mostly unknown; and low levels of medical evidence for published treatments and expert recommendations.

In folliculitis decalvans, imaging techniques using field emission scanning electron microscopy and confocal laser scanning microscopy have identified bacterial communities organized as biofilms in the infrainfundibular part of hair follicles [77]. It has long been known that Staphylococcus aureus is invariably found in folliculitis decalvans, but antibiotic treatments, irrespective of the type of antibiotic used, the protocol, and the treatment duration have all proven to not attain sustained results. Bacteria living in a biofilm have significantly different properties from free-floating bacteria of the same species. One benefit of this environment is increased resistance to antibiotics. Biofilms are involved in a wide variety of microbial infections in the body, and it has been found that bacterial biofilms may impair cutaneous wound healing and reduce topical antibacterial efficiency even in treating infected skin wounds. The presence of a bacterial biofilm at the interface of the hair shaft may provide an explanation for the chronicity and high relapse rate of folliculitis decalvans, and the rational basis for ablative laser therapy $[78,79]$ or surgical excision [80] for definitive healing.

Precision Medicine
Since structural changes in the course of scarring alopecia are irreversible, there is a clear need for early intervention. With the expanding technologies for dissecting the immunologic and molecular basis, there is hope for a deeper understanding of the underlying pathogenesis and novel therapeutic interventions. Among these, currently, microarray analysis is used to identify disease associated gene expression patterns with the aims of further clarification of nosologic classifications and development of targeted therapies of the scarring alopecias.

A prototypical example is the identification of decreased expression of peroxisome proliferator-activated receptor (PPAR) gamma in lichen planopilaris, suggesting PPARgamma-targeted therapy with oral pioglitazone for lichen planopilaris [81-83].

\section{Conclusions and Perspectives}

For centuries, physicians propagated the viability of a complex approach in the diagnosis and treatment of disease, while modern medicine, which boasts a wide range of diagnostic methods and variety of therapeutic procedures, stresses specification. This raises the issue of how to wholly evaluate the state of a patient who suffers from a number of diseases simultaneously? For this purpose, the concept of comorbidity was created, which is defined as presence of one or more additional diseases co-occurring with a primary disease, or the effect of such additional diseases [8486]. The effect of comorbid pathologies on clinical implications, diagnosis, prognosis, and therapy is polyhedral and patient specific. The interrelation of disease, age, and drug pathomorphisms greatly affects the clinical presentation and progress of the primary nosology, character, and severity of complications, and can challenge the diagnostic and therapeutic process. Therefore, the presence of comorbidity must be taken into account when selecting the algorithm of diagnosis and treatment, and the trichiatrist must participate with the other medical disciplines in the diagnosis and treatment of all types of hair problems as they may relate to systemic disease [87].

Further etiologies beyond the comorbid conditions are likely to be exposed by panomics [88], and these should be borne in mind when addressing the biological conditions contributing to hair loss, and when designing PMbased trichiatric treatment for optimum therapeutic efficacy. Finally, databases pertaining to the development and efficacy of PM must be analyzed and be used to form the basis of an evidence-based practice of personalized trichiatry.

Skin Appendage Disord 2019;5:338-343 


\section{Statement of Ethics}

The authors have no ethical conflicts to disclose.

\section{Disclosure Statement}

The authors have no conflicts of interest to disclose.

\section{References}

1 Guyatt G; Evidence-Based Medicine Working Group. Evidence-based medicine. A new approach to teaching the practice of medicine. JAMA. 1992 Nov;268(17):2420-5.

2 Timmerman L. What's in a Name? A Lot, When It Comes to Precision Medicine. Xconomy [Internet]. 2013. Available from: https:// xconomy.com/national/2013/02/04/whats-ina-name-a-lot-when-it-comes-to-precisionmedicine.

3 Trüeb RM, Vañó-Galván S, Kopera $\mathrm{D}$, et al. Trichologist, dermato-trichologist, or trichiatrist? A global perspective on a strictly medical discipline. Skin Appendage Disord. 2018 Oct; 4(4):202-7.

4 Marcińska M, Pośpiech E, Abidi S, Andersen JD, van den Berge M, Carracedo Á, et al.; EUROFORGEN-NoE Consortium. Evaluation of DNA variants associated with androgenetic alopecia and their potential to predict male pattern baldness. PLoS One. 2015 May; 10(5):e0127852.

5 Wakisaka N, Taira Y, Ishikawa M, Nakamizo Y, Kobayashi K, Uwabu M, et al. Effectiveness of finasteride on patients with male pattern baldness who have different androgen receptor gene polymorphism. J Investig Dermato Symp Proc. 2005 Dec;10(3):293-4.

6 Cauci S, Chiriacò G, Cecchin E, Toffoli G, Xodo S, Stinco G, et al. Androgen receptor (AR) gene (CAG)n and (GGN)n length polymorphisms and symptoms in young males with long-lasting adverse effects after finasteride use against androgenic alopecia. Sex Med. 2017 Mar;5(1):e61-71.

7 Goren A, Castano JA, McCoy J, Bermudez F, Lotti T. Novel enzymatic assay predicts minoxidil response in the treatment of androgenetic alopecia. Dermatol Ther (Heidelb). 2014 May-Jun;27(3):171-3.

8 Roberts J, Desai N, McCoy J, Goren A. Sulfotransferase activity in plucked hair follicles predicts response to topical minoxidil in the treatment of female androgenetic alopecia. Dermatol Ther (Heidelb). 2014 Jul-Aug;27(4): 252-4.

9 Goren A, Shapiro J, Roberts J, McCoy J, Desai $\mathrm{N}$, Zarrab Z, et al. Clinical utility and validity of minoxidil response testing in androgenetic alopecia. Dermatol Ther (Heidelb). 2015 JanFeb;28(1):13-6.

10 Deloche C, de Lacharrière O, Misciali C, Piraccini BM, Vincenzi C, Bastien P, et al. Histological features of peripilar signs associated with androgenetic alopecia. Arch Dermatol Res. 2004 Mar;295(10):422-8.

11 Whiting DA. Diagnostic and predictive value of horizontal sections of scalp biopsy specimens in male pattern androgenetic alopecia. J
Am Acad Dermatol 1993 May;28(5 Pt 1):75563.

12 Schwartz JR, Henry JP, Kerr KM, Flagler MJ, Page SH, Redman-Furey N. Incubatory environment of the scalp impacts pre-emergent hair to affect post-emergent hair cuticle integrity. J Cosmet Dermatol. 2018 Feb;17(1):105111. doi: 10.1111/jocd.12355. Epub 2017 May 14.

13 Reichel M, Heisig P, Kampf G. Identification of variables for aerobic bacterial density at clinically relevant skin sites. J Hosp Infect. 2011 May;78(1):5-10.

14 DeAngelis YM, Gemmer CM, Kaczvinsky JR, Kenneally DC, Schwartz JR, Dawson TL Jr. Three etiologic facets of dandruff and seborrheic dermatitis: malassezia fungi, sebaceous lipids, and individual sensitivity. J Investig Dermatol Symp Proc. 2005 Dec;10(3):295-7.

15 Gomez-Moyano E, Crespo-Erchiga V, Martínez-Pilar L, Godoy Diaz D, Martínez-García S, Lova Navarro M, Vera Casaño A. Do Malassezia species play a role in exacerbation of scalp psoriasis? J Mycol Med. 2014 Jun;24(2):87-92.

16 Waersted A, Hjorth N. Pityrosporum orbiculare - a pathogenic factor in atopic dermatitis of the face, scalp and neck? Acta Derm Venereol Suppl (Stockh). 1985;114:146-8.

17 Kim TY, Jang IG, Park YM, Kim HO, Kim CW Head and neck dermatitis: the role of Malassezia furfur, topical steroid use and environmental factors in its causation. Clin Exp Dermatol. 1999 May;24(3):226-31.

18 Schmid-Grendelmeier P, Scheynius A, Crameri R. The role of sensitization to Malassezia sympodialis in atopic eczema. Chem Immunol Allergy. 2006;91:98-109.

19 Darabi K, Hostetler SG, Bechtel MA, Zirwas $M$. The role of Malassezia in atopic dermatitis affecting the head and neck of adults. J Am Acad Dermatol. 2009 Jan;60(1):125-36.

20 Brodská P, Panzner P, Pizinger K, SchmidGrendelmeier P. IgE-mediated sensitization to malassezia in atopic dermatitis: more common in male patients and in head and neck type. Dermatitis. 2014 May-Jun;25(3):120-6.

21 Vexiau P, Chaspoux C, Boudou P, Fiet J, Jouanique $\mathrm{C}$, Hardy N, et al. Effects of minoxidil 2\% vs. cyproterone acetate treatment on female androgenetic alopecia: a controlled, 12-month randomized trial. Br J Dermatol. 2002 Jun; 146(6):992-9.

22 Price VH, Roberts JL, Hordinsky M, Olsen EA, Savin R, Bergfeld W, et al. Lack of efficacy of finasteride in postmenopausal women with androgenetic alopecia. J Am Acad Dermatol. 2000 Nov;43(5 Pt 1):768-76.

23 Shum KW, Cullen DR, Messenger AG. Hair loss in women with hyperandrogenism: four cases responding to finasteride. J Am Acad Dermatol. 2002 Nov;47(5):733-9.

24 Trüeb RM; Swiss Trichology Study Group. Finasteride treatment of patterned hair loss in normoandrogenic postmenopausal women. Dermatology. 2004;209(3):202-7.

25 Iorizzo M, Vincenzi C, Voudouris S, Piraccin BM, Tosti A. Finasteride treatment of female pattern hair loss. Arch Dermatol. 2006 Mar; 142(3):298-302.

26 Yeon JH, Jung JY, Choi JW, Kim BJ, Youn SW, Park KC, et al. $5 \mathrm{mg} /$ day finasteride treatment for normoandrogenic Asian women with female pattern hair loss. J Eur Acad Dermatol Venereol. $2011 \mathrm{Feb} ; 25(2): 211-4$

27 Boychenko O, Bernstein RM, Schweiger ES Finasteride in the treatment of female pattern (androgenic) alopecia: a case report and review of the literature. Cutis. 2012 Aug;90(2): 73-6.

28 Oliveira-Soares R, E Silva JM, Correia MP, André MC. Finasteride $5 \mathrm{mg}$ /day Treatment of Patterned Hair Loss in Normo-androgenetic Postmenopausal Women. Int J Trichology. 2013 Jan;5(1):22-5.

29 Won YY, Lew BL, Sim WY. Clinical efficacy of oral administration of finasteride at a dose of $2.5 \mathrm{mg} /$ day in women with female pattern hair loss. Dermatol Ther (Heidelb). 2018 Mar; 31(2):e12588

30 Olsen EA, Hordinsky M, Roberts JL, Whiting DA; Dermatologic Consortium for Women's Health. Female pattern hair loss. J Am Acad Dermatol. 2002 Nov;47(5):795.

31 Jackson D, Church RE, Ebling FJ. Hair diameter in female baldness. Br J Dermatol. 1972 Oct; $87(4): 361-7$.

32 Schmidt JB, Lindmaier A, Spona J. Hyperprolactinemia and hypophyseal hypothyroidism as cofactors in hirsutism and androgen-induced alopecia in women. Hautarzt. $1991 \mathrm{Mar}$ 42(3):168-72. German.

33 Schmidt JB. Hormonal basis of male and female androgenic alopecia: clinical relevance. Skin Pharmacol. 1994;7(1-2):61-6.

34 Arafah BM. Increased need for thyroxine in women with hypothyroidism during estrogen therapy. N Engl J Med. 2001 Jun;344(23): 1743-9.

35 Schindler AE. Thyroid function and postmenopause. Gynecol Endocrinol. 2003 Feb; 17(1):79-85.

36 del Ghianda S, Tonacchera M, Vitti P. Thyroid and menopause. Climacteric. 2014 Jun;17(3): 225-34.

37 Aydingöz IE, Ferhanoğlu B, Güney O. Does tissue iron status have a role in female alopecia? J Eur Acad Dermatol Venereol. 1999 Jul;13(1): 65-7. 
38 Chamberlain AJ, Dawber RP. Significance of iron status in hair loss in women. Br J Dermatol. 2003 Aug; 149(2):428.

39 Rushton DH. Decreased serum ferritin and alopecia in women. J Invest Dermatol. 2003 Nov; 121(5):xvii-xviii.

40 Kantor J, Kessler LJ, Brooks DG, Cotsarelis G. Decreased serum ferritin is associated with alopecia in women. J Invest Dermatol. $2003 \mathrm{Nov}$; 121(5):985-8

41 Trost LB, Bergfeld WF, Calogeras E. The diagnosis and treatment of iron deficiency and its potential relationship to hair loss. J Am Acad Dermatol. 2006 May;54(5):824-44.

42 Rushton DH, Dover R, Norris MJ, Gilkes JJ. Iron and hair loss in women; what is deficien$c y$ ? This is the real question! J Am Acad Dermatol. 2007 Mar;56(3):518-9.

43 Deloche C, Bastien P, Chadoutaud S, Galan P, Bertrais S, Hercberg S, et al. Low iron stores: a risk factor for excessive hair loss in non-menopausal women. Eur J Dermatol. 2007 Nov-Dec; 17(6):507-12.

44 Bregy A, Trueb RM. No association between serum ferritin levels $[\{G T\}] 10 \mathrm{microg} / \mathrm{l}$ and hair loss activity in women. Dermatology. 2008;217(1):1-6.

45 Moeinvaziri M, Mansoori P, Holakooee K, Safaee Naraghi Z, Abbasi A. Iron status in diffuse telogen hair loss among women. Acta Dermatovenerol Croat. 2009;17(4):279-84.

46 St Pierre SA, Vercellotti GM, Donovan JC, Hordinsky MK. Iron deficiency and diffuse nonscarring scalp alopecia in women: more pieces to the puzzle. J Am Acad Dermatol. 2010 Dec;63(6):1070-6.

47 Olsen EA, Reed KB, Cacchio PB, Caudill L. Iron deficiency in female pattern hair loss, chronic telogen effluvium, and control groups. J Am Acad Dermatol. 2010 Dec;63(6):991-9.

48 Park SY, Na SY, Kim JH, Cho S, Lee JH. Iron plays a certain role in patterned hair loss. J Korean Med Sci. 2013 Jun;28(6):934-8.

49 Tosti A, Bellavista S, Iorizzo M. Alopecia areata: a long term follow-up study of 191 patients. J Am Acad Dermatol. 2006 Sep;55(3):438-41.

50 Ikeda T. A new classification of alopecia areata. Dermatologica. 1965;131(6):421-45.

51 Cunliffe WJ, Hall R, Newell DJ, Stevenson CJ. Vitiligo, thyroid disease and autoimmunity. $\mathrm{Br}$ J Dermatol. 1968 Mar;80(3):135-9.

52 Cunliffe WJ, Hall R, Stevenson CJ, Weightman D. Alopecia areata, thyroid disease and autoimmunity. Br J Dermatol. 1969 Dec;81(12) $877-81$.

53 Puavilai S, Puavilai G, Charuwichitratana S, Sakuntabhai A, Sriprachya-Anunt S. Prevalence of thyroid diseases in patients with alopecia areata. Int J Dermatol. 1994 Sep;33(9):6323.

54 Seyrafi H, Akhiani M, Abbasi H, Mirpour S, Gholamrezanezhad A. Evaluation of the profile of alopecia areata and the prevalence of thyroid function test abnormalities and serum autoantibodies in Iranian patients. BMC Dermatol. 2005 Oct;5(1): 11

55 Kumar B, Sharma VK, Sehgal S. Antismooth muscle and antiparietal cell antibodies in Indi- ans with alopecia areata. Int J Dermatol. 1995 Aug;34(8):542-5.

56 Werth VP, White WL, Sanchez MR, Franks AG. Incidence of alopecia areata in lupus erythematosus. Arch Dermatol. 1992 Mar;128(3): 368-71.

57 Corazza GR, Andreani ML, Venturo N, Bernardi M, Tosti A, Gasbarrini G. Celiac disease and alopecia areata: report of a new association. Gastroenterology. 1995 Oct;109(4): 1333-7.

58 Fessatou S, Kostaki M, Karpathios T. Coeliac disease and alopecia areata in childhood. J Paediatr Child Health. 2003 Mar;39(2):152-4.

59 Zampetti M, Filippetti R. Alopecia areata and celiac disease. G Ital Dermatol Venereol. 2008 Apr;143(2):168

60 Ertekin V, Tosun MS, Erdem T. Screening of celiac disease in children with alopecia areata. Indian J Dermatol. 2014 May;59(3):317.

61 Park H, Kim CW, Kim SS, Park CW. The therapeutic effect and the changed serum zinc level after zinc supplementation in alopecia areata patients who had a low serum zinc level. Ann Dermatol. 2009 May;21(2):142-6.

62 Abdel Fattah NS, Atef MM, Al-Qaradaghi SM. Evaluation of serum zinc level in patients with newly diagnosed and resistant alopecia areata. Int J Dermatol. 2016 Jan;55(1):24-9.

63 Yilmaz N, Serarslan G, Gokce C. Vitamin D concentration are decreased in patients with alopecia areata. Vitam Trace Elem. 2012;1: 105-9.

64 d'Ovidio R, Vessio M, d'Ovidio FD. Reduced level of 25-hydroxyvitamin $\mathrm{D}$ in chronic/relapsing Alopecia Areata. Dermatoendocrinol. 2013 Apr;5(2):271-3.

65 Aksu Cerman A, Sarikaya Solak S, Kivanc Altunay I. Vitamin D deficiency in alopecia areata. Br J Dermatol. 2014 Jun;170(6):1299-304.

66 Bakry OA, El Farargy SM, El Shafiee MK, Soliman A. Serum Vitamin D in patients with alopecia areata. Indian Dermatol Online J. 2016 Sep-Oct;7(5):371-7.

67 Stewart MI, Smoller BR. Alopecia universalis in an HIV-positive patient: possible insight into pathogenesis. J Cutan Pathol. 1993 Apr; 20(2):180-3.

68 Price VH, Colombe BW. Heritable factors distinguish two types of alopecia areata. Dermatol Clin. 1996 Oct;14(4):679-89.

69 Petukhova L, Duvic M, Hordinsky M, Norris D, Price V, Shimomura Y, et al. Genome-wide association study in alopecia areata implicates both innate and adaptive immunity. Nature. 2010 Jul;466(7302):113-7.

70 Betz RC, Petukhova L, Ripke S, Huang H, Menelaou A, et al. Genome-wide meta-analysis in alopecia areata resolves HLA associations and reveals two new susceptibility loci. Nat Commun. 2015; 22; 6:5966 https://doi. org/10.1038/ncomms6966.

71 Divito SJ, Kupper TS. Inhibiting Janus kinases to treat alopecia areata. Nat Med. 2014 Sep; 20(9):989-90.

72 Craiglow BG, King BA. Killing two birds with one stone: oral tofacitinib reverses alopecia universalis in a patient with plaque psoriasis.
J Invest Dermatol. 2014 Dec;134(12):298890.

73 Xing L, Dai Z, Jabbari A, Cerise JE, Higgins CA, Gong W, et al. Alopecia areata is driven by cytotoxic $\mathrm{T}$ lymphocytes and is reversed by JAK inhibition. Nat Med. 2014 Sep;20(9): 1043-9.

74 Jabbari A, Dai Z, Xing L, Cerise JE, Ramot Y, Berkun Y, et al. Reversal of alopecia areata following treatment with the JAK1/2 inhibitor Baricitinib. EBioMedicine. 2015 Feb;2(4):3515.

75 Liu LY, Craiglow BG, Dai F, King BA. Tofacitinib for the treatment of severe alopecia areata and variants: A study of 90 patients. J Am Acad Dermatol. 2017 Jan;76(1):22-8.

76 Craiglow BG, Liu LY, King BA. Tofacitinib for the treatment of alopecia areata and variants in adolescents. J Am Acad Dermatol. 2017 Jan; 76(1):29-32.

77 Matard B, Meylheuc T, Briandet R, Casin I, Assouly P, Cavelier-balloy B, et al. First evidence of bacterial biofilms in the anaerobe part of scalp hair follicles: a pilot comparative study in folliculitis decalvans. J Eur Acad Dermatol Venereol. 2013 Jul;27(7):853-60.

78 Parlette EC, Kroeger N, Ross EV. Nd:YAG laser treatment of recalcitrant folliculitis decalvans. Dermatol Surg. 2004 Aug;30(8):1152-4.

79 Meesters AA, Van der Veen JP, Wolkerstorfer A. Long-term remission of folliculitis decalvans after treatment with the long-pulsed Nd:YAG laser. J Dermatolog Treat. 2014 Apr; 25(2):167-8.

80 Trüeb RM, Pericin M, Hafner J, Burg G. Tufted hair folliculitis. Hautarzt. 1997 Apr;48(4):2669. German.

81 Karnik P, Tekeste Z, McCormick TS, Gilliam AC, Price VH, Cooper KD, et al. Hair follicle stem cell-specific PPARgamma deletion causes scarring alopecia. J Invest Dermatol. 2009 May; 129(5):1243-57.

82 Harries MJ, Paus R. Scarring alopecia and the PPAR-gamma connection. J Invest Dermatol. 2009 May;129(5):1066-70.

83 Mirmirani P, Karnik P. Lichen planopilaris treated with a peroxisome proliferator-activated receptor gamma agonist. Arch Dermatol. 2009 Dec;145(12):1363-6.

84 Feinstein AR. The pre-therapeutic classification of co-morbidity in chronic disease. J Chronic Dis. 1970 Dec;23(7):455-68.

85 Valderas JM, Starfield B, Sibbald B, Salisbury C, Roland M. Defining comorbidity: implications for understanding health and health services. Ann Fam Med. 2009 Jul-Aug;7(4):35763.

86 Mangin D, Heath I, Jamoulle M. Beyond diagnosis: rising to the multimorbidity challenge. BMJ. 2012 Jun;344:e3526.

87 Jakovljević M, Ostojić L. Comorbidity and multimorbidity in medicine today: challenges and opportunities for bringing separated branches of medicine closer to each other. Psychiatr Danub. 2013 Jun;25 Suppl 1:18-28.

88 Sandhu C, Qureshi A, Emili A. Panomics for Precision Medicine. Trends Mol Med. 2018 Jan;24(1):85-101. 